\title{
El nuevo estatuto de autonomía de Cataluña de 2006, EN EL MARCO DE LAS REFORMAS ESTATUTARIAS EN ESPAÑA
}

\author{
Marc Carrillo*
}

RESUMEN: Desde hace tres años, en España se ha iniciado un proceso de reforma de los Estatutos de Autonomía de algunas de las 17 Comunidades Autónomas que integran el modelo de Estado políticamente descentralizado, diseñado por la Constitución de 1978. No bay duda que el que ha suscitado más controversia en el debate jurídico y también político, ha sido el Estatuto de Cataluña, ya aprobado en 2006. Los temas de mayor relevancia han sido los relativos a la incorporación de una Carta propia de Derechos; la determinación material y funcional de las competencias para el ejercicio del autogobierno, así como las relaciones con el Estado y la Unión Europea y el sistema de financiación.

Palabras clave: Autonomía - Federalismo - Descentralización Organización territorial - Estado compuesto.

\section{The new Autonomy Statute of Catalonia since 2006, BASED ON THE STATUTORY REFormS IN SPAIN}

ABSTRACT: Three years ago, a process of reform to the Statutes of Autonomy of some of the 17 Autonomous Communities that make up the model of politically decentralized State, designed by the Constitution of 1978, begun in Spain. Doubtless, the one that has sparked off more controversy in the legal and also the political grounds has been the Statute of Catalonia, approved since 2006. The subjects of greatest relevance have been those related to the incorporation of a Letter of Rights; the material and functional determination of the competences for the exercise of the self-government, as well as the relationships with the State, the European Union, and the financing system.

KEY WORDS: Autonomy - Federalism - Decentralization - Local government organization, Compound State.

Catedrático de Derecho Constitucional de la Universidad Pompeu Fabra. Barcelona (España). DEA Institut d'Études Politiques de Paris (FNSP). Miembro del Consell Consultiu de la Generalitat de Catalunya. Correo electrónico: mcarrillo@cconsultiu.es Fecha de recepción: 27 de febrero de 2008.

Fecha de aprobación: 15 de abril de 2008 
SUMARIO: I. El contexto político-constitucional del nuevo Estatuto de Catalunya de 2006. II. La incorporación de una Carta de Derechos. III. La competencias para el ejercicio del autogobierno. IV. Las relaciones con el Estado y la Unión Europea. V. El sistema de financiación. VI. Bibliografía.

\section{El contexto político-Constitucional del nuevo Estatuto de Catalunya de 2006}

Después de 30 años de recuperada la democracia, España se encuentra inmersa en proceso de reformas de una parte de los Estatutos de autonomía de las 17 Comunidades Autónomas (CCAA) que integran el Estado. El caso de la Catalunya ha tenido una especial relevancia en el ámbito del debate jurídico, sin duda, en el contexto político ${ }^{1}$.

El 9 de agosto de 2006 entró en vigor el nuevo Estatuto de autonomía de Cataluña. Con el Decreto 3006/2006, de 20 de julio, del Departamento de la Presidencia de la Generalitat de Catalunya, por el cual se da publicidad a la Ley Orgánica 6/2006, de 19 de julio, de reforma del Estatuto de autonomía de Cataluña, se inauguraba un nuevo marco jurídico del autogobierno.

La reforma del Estatuto de 1979, materialmente ha supuesto un nuevo Estatuto. La derogación de la Ley Orgánica 4/1979, de 18 de diciembre, de Estatuto de autonomía de Cataluña ha dado como resultado una nueva norma institucional básica que sustancialmente constituye un instrumento diferente para regular el autogobierno. Su estructura formal y su contenido permiten afirmar que la Ley Orgánica 6/2006, ha generado un nuevo ámbito normativo de la autonomía política.

De los cuatro Títulos de que constaba el Estatuto de 1979, el nuevo contiene siete. Se han añadido 3 Títulos nuevos que son los referidos a: los derechos, deberes y principios rectores (Título I); el Poder Judicial en Cataluña (Título III) y las relaciones institucionales de la Generalitat (Título V). Su extensión es mucho más amplia que la anterior. Así, frente a los 57 artículos, 7 Disposiciones Adicionales y 8 Disposiciones Transitorias del texto de 1979, el Estatuto ahora aprobado contiene 223 artículos, 15 Disposiciones Adicionales, 2 Disposiciones Transitorias, 1 Disposición Derogatoria y 4 Disposiciones Finales. El resultado ha sido un Estatuto dotado, sin duda, de una mayor densidad normativa.

El proceso de elaboración del nuevo Estatuto se inició a partir de unas propuestas muy genéricas elaboradas por los partidos políticos con representación en el Parlamento de Catalunya, a excepción del Partido Popular

En el momento de redactar este artículo (febrero de 2008), además del Estatuto de Catalunya, han sido reformados también los Estatutos de las Comunidades Autónomas siguientes: Comunidad Valenciana, Islas Baleares, Andalucía, Aragón y Castilla-León. 
que no aportó ninguna. Pero mucha mayor relevancia tuvieron los trabajos aportados por el Instituto de Estudios Autonómicos (IEA). El IEA es un organismo adscrito al Departamento de Relaciones Institucionales y Participación del Gobierno de la Generalitat. Fue creado el año 1984 con la finalidad de dotar a la Generalitat de un instrumento de estudio y de investigación en materia de autonomías territoriales que contribuyera a la implantación del autogobierno de Cataluña. Sus trabajos a disposición de la Ponencia parlamentaria fueron un muy fundamentado y extenso trabajo jurídico que abordó todos el contenido de la reforma estatutaria, salvo la parte relativa a la financiación (Hacienda, presupuesto y patrimonio de la Generalitat y haciendas locales).

El proceso de la reforma del Estatuto de 1979 se desarrolló de acuerdo con el procedimiento establecido en su artículo 56 y también en el artículo 147.3 de la Constitución española (CE): "La reforma del Estatuto se ajustará al procedimiento que ellos mismos establezcan y requerirá, en cualquier caso, la aprobación de las Cortes Generales por ley orgánica"); el artículo 151.2 CE, además de la Resolución del Congreso de los Diputados, de 16 de marzo de 1993 , sobre procedimiento a seguir para la tramitación de la reforma de los Estatutos de autonomía (Apartado II).

Según el artículo 115 del Reglamento del Parlamento de Catalunya, el trámite parlamentario de la Propuesta de reforma del Estatuto de $1979^{2}$ siguió las fases de ponencia, aprobación del dictamen para la Comisión, y a requerimiento del Parlamento, se emitió un posterior dictamen del Consejo Consultivo antes de la aprobación final por el Pleno de la cámara autonómica.

El Consejo Consultivo es un órgano de garantía estatutaria de carácter consultivo y no jurisdiccional, que ejerce un control previo de carácter no vinculante sobre las leyes catalanas así como también sobre las leyes estatales en caso de recurso de inconstitucionalidad presentado ante el Tribunal Constitucional por la Generalitat, que es la institución de autogobierno de Catalunya.

El dictamen del Consejo Consultivo sobre el texto del Dictamen de la Comisión de Organización y Administración de la Generalitat y Gobierno Local sobre la Proposición de ley orgánica de reforma del Estatuto de 1979 fue tenido en cuenta en buena parte por el Pleno del Parlamento. Este colegio de garantía estatutaria concluyó que el contenido total o parcial de veinte artículos aprobados por la Comisión parlamentaria era inconstitucional y además, en treinta nueve supuestos adoptaba una conclusión de carácter interpretativo. Esto es, los preceptos mencionados eran constitucionales si se interpretaban en el sentido que el Consejo proponía. El dictamen

2

El Reglamento del Parlamento, aprobado el 22 de diciembre de 2005 (BOPC núm. 271, de 29 de diciembre de 2005), regula en su artículo 123 el procedimiento de reforma del Estatuto. 
fue aprobado por mayoría de los consejeros e incorporó votos particulares referidos, especialmente, al reconocimiento de los denominados derechos históricos de Catalunya, el sistema de financiación y el carácter laico de la enseñanza.

Además de una fuerte controversia política que no corresponde ser analizada aquí, la reforma estatutaria catalana ha suscitado un amplio debate jurídico, iniciado antes del trámite parlamentario en la Comunidad Autónoma catalana y después en las Cortes Generales. La controversia jurídica se ha centrado en los temas siguientes: determinar si a través de su reforma, el Estatuto de una Comunidad Autónoma puede precisar el alcance material y funcional de las competencias; establecer criterios tanto sobre la financiación de la autonomía política; la regulación de las relaciones de la Generalitat con el Estado y la Unión Europea, la incorporación de una carta de derechos para así limitar la acción de los poderes públicos. Un sector de la doctrina ha considerado que esta opción de la reforma estatutaria es adecuada a la CE porque en ningún caso condiciona al poder legislativo del Estado, mientras que en otros ámbitos, por el contrario, se considera que las previsiones de la reforma estatutaria catalana suponen una reforma encubierta de la CE.

Seguramente, el primer documento que sirvió de base para un amplio debate sobre la reforma estatutaria referida fue el Informe sobre el autogobierno, editado por el Instituto de Estudios Autonómicos en el 2003, de lo que serían coautores cuatro catedráticos de Derecho Constitucional y Derecho Administrativo de universidades públicas catalanas ${ }^{3}$. A este primer Informe siguió, posteriormente, otro trabajo elaborado por profesores de Derecho Público (Constitucional, Administrativo y Financiero) procedentes de universidades de fuera de Catalunya, bajo el título Estudios sobre la reforma del Estatuto, también editado por el Instituto ${ }^{4}$.

En este contexto de debate académico hay que hacer referencia también al Foro sobre la Estructura territorial del Estado, organizado por el Centro de Estudios Políticos y Constitucionales, órgano dependiente de la Presidencia del Gobierno del Estado, que constituye un ámbito de reflexión jurídica sobre temas sectoriales de la autonomía política como, por ejemplo, las el concepto de nación, competencias, la financiación, las declaraciones de derechos, la reforma del Senado, la administración local, etc. y que ha tenido y sigue teniendo como protagonista indiscutible a la reforma estatutaria catalana.

Asimismo, cabe también destacar los informes promovidos por el Ministerio de Administraciones Públicas, los artículos en revistas especiagobierno. Barcelona: Institut d'Estudis Autonòmics. Generalitat de Catalunya.

4 VV.AA. (2004) Estudios sobre la reforma del Estatuto. Barcelona: Institut d'Estudis Autonòmics. Generalitat de Catalunya. 
lizadas en Derecho público sobre las reformas estatutarias o los seminarios y debates académicos organizados en los más diversos ámbitos universitarios y también políticos. Por ejemplo, los informes que el PSOE encargó a cuatro catedráticos de Derecho Constitucional sobre el texto aprobado a la cámara catalana, un resumen del cual ${ }^{5}$ fue dado a conocer el 24 de octubre de 2005, bajo el título Conclusiones Generales del Dictamen sobre la Propuesta de reforma del Estatuto de Cataluña.

En el marco del debate jurídico, destaca el trabajo firmado por el Director del IEA de la Generalidad de Cataluña, C. Viver Pi-Sunyer, "En defensa de los Estatutos de autonomía como normas jurídicas delimitadoras de competencias. Contribución a una polémica jurídico-constitucional"6.

De acuerdo con lo que prevé el artículo $147.3 \mathrm{CE}$, una vez aprobada la Propuesta de reforma del Estatuto por el Parlamento de Catalunya el 30 de septiembre de 2005 por una amplia mayoría (sobre 135 diputados, 120 votaron a favor - $\mathrm{CiU}$, PSC, ERC y IC- y 15 -PP- en contra), para adquirir validez tenía que ser aprobado de forma definitiva mediante ley orgánica por el Parlamento del Estado, las Cortes Generales.

Teniendo en cuenta el carácter del Estatuto, como norma institucional básica de la Comunidad Autónoma, es el resultado de la concurrencia de dos voluntades parlamentarias, la del Parlamento de Cataluña y la emitida por las Cortes Generales, el otoño de 2005 el debate político se trasladó a la institución legislativa estatal donde debía proseguir hasta ser aprobado por ley orgánica.

En el trámite parlamentario en las Cortes Generales, la fuerte oposición del grupo parlamentario del Partido Popular al Proyecto de reforma se manifestó desde el primer momento en que la iniciativa legislativa fue admitida a trámite. El citado grupo presentó un recurso de amparo contra el Acuerdo de la mesa del Congreso de los Diputados de 18 de octubre de 2005, por el cual se calificó la propuesta de reforma del Estatuto presentada por el Parlamento catalán como a propuesta de reforma de Estatuto de Autonomía, se admitió a trámite y se acordó tramitarla por el procedimiento establecido en el apartado II de la Resolución de la Presidencia del Congreso de los Diputados de 16 de marzo de 1993. En esencia, el grupo parlamentario del PP denunciaba que estos Acuerdos producían lesión de los derechos fundamentales de los diputados ex artículo 23.2 CE, es decir, el derecho del ciudadanos a acceder en condiciones de igualdad a las funciones y a los cargos públicos, con los requisitos que las leyes señalen y más precisamente en aquello que afectaba en el ius in officium. La razón principal del grupo popular era que si se trataba de una reforma encubier-

Vid. www.psoe.es

Viver Pi-Sunyer, C. (2005) "En defensa de los Estatutos de autonomía como normas jurídicas delimitadoras de comperencias. Contribución a una polémica jurídico-constitucional". Revista de Estudios Autonómicos y Federales, $\mathrm{N}^{\circ} 1$. 
ta de la CE, el procedimiento que el Congreso estaba aplicando era incorrecto y por tanto vulneraba los derechos de los parlamentarios. Sin embargo, por un Auto de 15 de marzo de 2006, el Tribunal Constitucional, por mayoría, decidió no admitir el recurso de amparo y archivar las actuaciones. Su resolución se basó en los argumentos siguientes: 1) El recurso de amparo no puede tener por objeto el contenido del Estatuto propuesto, dado que la única virtualidad jurídica de los Acuerdos de la Mesa era la de iniciar en el Congreso del Diputados el procedimiento parlamentario de tramitación de la propuesta de reforma. 2) El simple enunciado de una proposición contraria a la Constitución no constituye objeto de enjuiciamiento por parte del TC. Lo que es relevante a efectos de la jurisdicción constitucional, es el contraste entre la Constitución y las proposiciones jurídicas que tengan la forma requerida en cada caso para la Ley Orgánica en la regulación de los diferentes constitucionales. En consecuencia, pretender que el TC se pronuncie sobre el contenido de la propuesta de reforma del Estatuto de Autonomía supondría convertir en este caso la demanda de amparo en una especie de remedio jurisdiccional preventivo. 3) El TC solamente puede conocer y juzgar el contenido de la Propuesta de reforma del Estatuto de Cataluña en el caso de que sea finalmente aprobada. 4) Un proyecto de norma inconstitucional no es, como tal, un proyecto inconstitucional. La antijuridicidad se predica de normas definitivamente incorporadas al ordenamiento, no de simples proyectos de normas ni tampoco de la sola intención de producir normas. En consecuencia, mientras que no se agota al procedimiento parlamentario iniciado, no hay más inconstitucionalidad que la que resulte de la infracción de las normas que disciplinan este procedimiento. 4) Con relación a la violación del "ius in officium" denunciado por el grupo parlamentario popular, el TC establece que invocar el artículo 23 CE para impedir la tramitación de una propuesta de reforma de un Estatuto de Autonomía con el argumento de que, dado que la Propuesta de reforma es contraría en la Constitución, la tramitación que merece es la reservada por la revisión constitucional, supondría, de ser aceptado este planteamiento, que la iniciativa legislativa se vería sencillamente paralizada por cualquier Diputado o grupo parlamentario que denunciara la inconstitucionalidad material de cualquier proyecto o proposición para exigir como requisito obligado, la aplicación de uno de los procedimientos del Título X de la CE. Supondría, en definitiva, que desvirtuando la lógica parlamentaria basada en el principio de la mayoría, la minoría estaría en disposición de privar a la mayoría de la suya verdadera condición de tal, haciendo necesaria la constitución de las mayorías especialmente reforzadas que solamente se exigen para los supuestos singulares que la CE ha previsto (artículos 167 y 168). 5). También en relación en el artículo 23.2 $\mathrm{CE}$, no se puede apreciar un supuesto de tratamiento desigual ni una sospecha de discriminación ad personam que pudiera sufrir el grupo recurrente y sus miembros, pues los Acuerdos recurridos responden al criterio ya uti- 
lizado por la mesa del Congreso de los Diputados en ocasiones precedentes, en concreto en relación con la calificación de la Propuesta de reforma del Estatuto de Autonomía de la Comunidad de Euskadi y con la Propuesta de reforma del Estatuto de Autonomía de la Comunidad Valenciana.

Los intentos de impedir que la reforma del Estatuto siguiese su curso parlamentario prosiguieron con un Informe negativo emitido de oficio por el Consejo General de Poder Judicial (CGPJ), el órgano de gobierno de la magistratura. En efecto, el Pleno del CGPJ aprobó un Estudio sobre la Propuesta de reforma del Estatuto de autonomía de Cataluña, en el que denunciaba un buen número de motivos de inconstitucionalidad en el Título III, es decir, el relativo al Poder Judicial en Cataluña. Este Estudio había sido elaborado de forma irregular por la Comisión de Estudios e Informes del CGPJ porque, de acuerdo con lo que prevé el artículo 109 de la Ley Orgánica del Poder Judicial (LOPJ), para emitir dicho informe se requería la previa solicitud de las Cortes Generales que, sin embargo, nunca se produjo.

Después de largas jornadas de debate y negociación política el 30 de marzo de 2006 el Boletín Oficial de las Cortes Generales publicó el texto definitivo aprobado por el Pleno del Congreso de los Diputados. El resultado de la votación superó la mayoría absoluta requerida, con 189 votos a favor (PSOE, CiU, IU-IC, etc.), 154 en contra (el PP además de Esquerra Republicana de Catalunya -ERC-, un partido de carácter independentista) y 2 abstenciones.

Los cambios registrados en el texto respecto de lo que había sido aprobado por el Parlamento de Cataluña el 30 de septiembre de 2005 afectaron especialmente al Preámbulo, el Título Preliminar, el Título referido sobre el Poder Judicial en Cataluña, el Título IV, relativo a la regulación de las competencias de la Generalitat, el Título V, sobre las relaciones institucionales de la Generalitat, el Título VI que regula la financiación así como también una buena parte de las Disposiciones Adicionales.

El texto aprobado por la Cámara baja pasó al Senado que, tras rechazar una propuesta de veto presentada por el PP, lo aprobó sin ninguna modificación, por una ajustada mayoría formada por los mismos partidos políticos que habían dado su apoyo en el Congreso (128 a favor, 125 en contra y 6 abstenciones).

De acuerdo con el art. 151.5 CE la Propuesta de reforma fue sometida a referéndum en Catalunya el 18 de junio de 2006, que con un 48,85\% de participación registró el siguiente resultado: $73,23 \%$ de votos afirmativos, $20,57 \%$ negativos, $5,28 \%$ votos en blanco y $0,89 \%$ de votos nulos 7 .

Para conocer el proceso jurídico de aprobación del Estatuto, véase: L'EsTATUT D'AuTONOMIA de Catalunya de 2006. Edició a Càrrec de Marc Carrillo. Textes Jurídics (2007). Barcelona: Institut d'Estudis Autonòmics; TorNos, J. (2007) Los Estatutos de Autonomía de Cataluña. Madrid: Iustel. 
El nuevo Estatuto ya vigente comporta novedades importantes respecto del aprobado en 1979. A modo de una breve exposición descriptiva hay que destacar: la incorporación al Preámbulo de la definición de Cataluña como nación, reconocida previamente por el Parlamento de Cataluña; la previsión en el Título I, de derechos, deberes y principios rectores, vinculados a las competencias y como expresión de un modelo de autogobierno y al mismo tiempo límite a la actuación de los poderes públicos; la organización al Título II de las instituciones, incorporando una regulación más detallada de su régimen jurídico; la regulación al Título III del Poder Judicial en Cataluña, de acuerdo con las previsiones de la Ley Orgánica del Poder Judicial, que requerirá una futura reforma, y la precisión de las competencias no jurisdiccionales en aquello que forma parte de la llamada administración de la Administración de Justicia; el Título IV prevé un. nuevo régimen las competencias, basado en una tipología que el Estatuto define y en una precisión funcional y material de los ámbitos materiales del autogobierno; el Título $\mathrm{V}$, que regula las relaciones institucional de la Generalitat, con el Estado, las otras Comunidades Autónomas y con la Unión Europea, así como también la acción exterior de la Generalitat; y, finalmente, el Título VI, que modifica el régimen de financiación, en lo que entre otros aspectos destaca la creación de una Agencia Tributaria propia, en régimen de colaboración con la Agencia estatal.

Una vez entrado en vigor, el Estatuto de 2006 ha sido objeto de varios recursos de inconstitucionalidad presentados por el PP, el Defensor del Pueblo y las CCAA de Murcia, Comunidad Valenciana, Aragón e Islas Baleares. El PP presentó un extenso recurso de inconstitucionalidad contra un amplio número de preceptos del nuevo Estatuto de Autonomía de Cataluña que, en sustancia, supone un cuestionamiento general de todo el contenido de la reforma estatutaria, por considerar que se trata de una reforma encubierta de la CE. En el mismo sentido se manifiesta el recurso presentado por el Defensor del Pueblo, el ombudsman que a pesar de solo disponer de competencias limitadas a la garantía de los derechos y libertades constitucionales, con esta atípica acción procesal también cuestiona la práctica integridad del Estatuto. Por su parte, los motivos de inconstitucionalidad alegados por las CCAA citadas se refieren a la competencia del Estado en materia de aguas, el régimen del Archivo de la Corona de Aragón, el régimen de financiación y el principio de bilateralidad EstadoGeneralitat.

Asimismo, como consecuencia del proceso de reforma estatutaria en Catalunya se han producido incidencias de especial trascendencia en el seno del Tribunal Constitucional, en un contexto político y jurisdiccional especialmente enrarecido. En este sentido, destaca el Auto de 2 de febrero de 2007 por el que la mayoría del Pleno del TC recusó al magistrado $\mathrm{Pa}$ blo Pérez Tremps, apartándolo del conocimiento del recurso contra el Estatuto catalán. La razón de esta excepcional medida fue que, con anteriori- 
dad a su condición de magistrado del TC, había realizado un estudio doctrinal publicado por el Instituto de Estudios Autonómicos de la Generalidad de Catalunya antes que se hubiese iniciado el proceso de reforma estatutaria. Con esta singular y controvertida decisión, el TC varió su doctrina anterior $^{8}$ con unos efectos demoledores pues, de hecho, con el nuevo criterio se impide ser magistrado del TC a cualquier profesor de Derecho que haya opinado en sede doctrinal acerca de normas que, eventualmente, puedan ser objeto de juicio constitucional.

La decisión final del TC sobre la reforma del Estatuto catalán sigue pendiente de sentencia? .

\section{La incorporación de una Carta de Derechos ${ }^{10}$}

Sin duda, una de las novedades que aporta el Estatuto de Autonomía de Cataluña ha sido la incorporación en su contenido dispositivo, de un Título I, cuya rúbrica es: Derechos, deberes y principios rectores. Se trata de un Título dividido en cinco capítulos: el primero, incluye derechos y deberes del ámbito civil y social; el segundo, derechos del ámbito político y de la administración; el tercero, derechos y deberes lingüísticos; el cuarto se refiere a las garantías de los derechos estatutarios y el quinto contiene un amplio y prolífico listado de principios rectores. La constitucionalidad de esta previsión estatutaria se fundamenta en los siguientes argumentos:

Auto de de 2 de febrero de 2006

A la fecha de entrega de este trabajo a Giurisprudenza Costitzionale.

Para seguir el debate sobre la constitucionalidad o no de la previsión estatutaria de una Carta de Derechos véase a CARrillo, M. (2007) "Los derechos, un contenido constitucional de los Estatutos de Autonomía”. REDC No 80, pp. 49-73; DíEz-PiCAZo, L. M ${ }^{a}$ (2006) “¿Pueden los Estatutos de Autonomía declarar derechos, deberes y principios?, REDC $\mathrm{N}^{\circ} 78$, pp. 63-75; CaAmaño, F. (2007) "Sí, pueden (Declaraciones de derechos y Estatutos de Autonomía)", REDC $\mathrm{N}^{\circ} 79$, pp. 33-46; Ferreres Comella, V./ Biglino Campos, P./ Carrillo, M. (2006) Derechos, deberes y principios en el nuevo Estatuto de Autonomía de Cataluña. Madrid: Foro Estructura Territorial No 8, CEPC; García Torres, J. (2006) "Los derechos estatutarios en la propuesta catalana de reforma". En El Estado autonómico (Actas de las XI Jornadas de la Asociación de Letrados del Tribunal Constitucional). Madrid: CEPC, pp. 57-74. CASTELLÀ ANDreu, J.M. (2005) "El reconocimiento y garantía de los derechos y libertades en los Estados compuestos. Una aproximación comparada". En Aparicio, M. A. (Editor) Derechos y libertades en los Estados compuestos. Barcelona: Atelier, pp. 11-38; Català I Bas, A. H. (2005) "La inclusión de una carta de derechos en los estatutos de autonomía". Revista Española de la Función Consultiva No 4, València, pp. 181-204; Martín-Retortillo Baquer, L. (2005) "Derechos humanos y Estatutos de autonomía". Repertorio Aranzadi del Tribunal Constitucional $N^{\circ} 3$, p. 1; Ortega Santiago, C. (2006) "Los nuevos Estatutos de Autonomía de las regiones italianas". Revista Española de Derecho Constitucional, $\mathrm{N}^{\circ} 78$, septiembre-diciembre, pp. 43-61; Rossi, E. (2005) "Derechos de libertad y Estatutos regionales. La situación italiana". En Aparicio, M. A. (editor) Derechos y libertades en los Estados compuestos.. Barcelona: Atelier, pp. 201-234. 


\section{Una declaración de derechos forma parte del contenido posible de los Estatutos de Autonomía}

En el marco del ordenamiento jurídico español que un Estatuto de autonomía pueda contemplar una declaración específica de derechos no puede ofrecer $a b$ initio reproche constitucional. El contenido del Estatuto, como norma institucional básica de la Comunidad Autónoma es diverso y si bien la Constitución establece un mínimo imprescindible y necesario para la configuración institucional de la autonomía política, ello no comporta la exclusión de un contenido posible que el legislador estatuyente puede decidir incorporar a su parte dispositiva, a fin de atribuir un mayor significado al ejercicio del autogobierno, es decir, al objeto de expresar de forma más precisa el alcance de la autonomía política que el Estatuto como norma institucionaliza.

La naturaleza jurídica del Estatuto de Autonomía de Cataluña determina su contenido. En su condición de norma institucional básica, de carácter pactado, fruto de la confluencia de dos legitimidades democráticas, ambas derivadas de la Constitución, su contenido es indisponible de forma unilateral para el legislador ordinario, ya sea el estatal o el autonómico. Ha de ser a través del procedimiento de reforma estatutaria, como puede llevarse a cabo la determinación o reconsideración de su contenido, de acuerdo con las previsiones que al respecto establece la norma constitucional. De acuerdo con esta, el contenido de los estatutos no viene tasado de forma cerrada sino que a partir de unos elementos comunes el contenido puede ser variable, en función de la voluntad expresada por el legislador estatuyente.

Así, y de acuerdo con la línea argumental establecida por el Consell Consultiu de la Generalitat de Catalunya en su dictamen n ${ }^{\circ} 269$ de 1 de septiembre de 2005, Fundamento I, los Estatutos deben tener un contenido necesario que viene necesariamente impuesto por la CE norma de la que derivan; pueden tener un contenido adicional cuya concreción depende de la libre disposición del legislador de incorporar determinadas competencias, siempre que dicho contenido presente una relación de conexión suficiente con el contenido preceptivamente exigido por la CE. Y finalmente, los Estatutos también pueden tener también un contenido posible, en la medida en que su inclusión sea un complemento o una definición más precisa del alcance del contenido necesario que los estatutos han de tener. En el cumplimiento de este requisito radica la legitimidad constitucional de determinados contenidos que pueden ser incluidos en los Estatutos.

El contenido necesario preceptuado por la CE y por tanto no disponible para el legislador estatuyente viene determinado por el artículo 147.1 $\mathrm{CE}$, que como es sabido establece que los estatutos de autonomía deberán contener: la denominación de la Comunidad Autónoma que mejor corresponda a su identidad histórica, la delimitación del territorio, la denomi- 
nación, organización y sede de las instituciones autónomas propias y las competencias asumidas dentro del marco establecido en la CE y las bases para el traspaso de los servicios correspondientes a las mismas. Asimismo, es preciso añadir a este contenido que también de acuerdo con lo que establece el artículo 69.5 CE, el Estatuto deberá regular el procedimiento de designación de los senadores que representen a la Comunidad Autónoma en la Cámara alta.

Un segundo ámbito del contenido de los Estatutos es aquel que la CE habilita para que, en su caso, la norma institucional básica de la Comunidad Autónoma pueda contener, de forma adicional y disponible también aspectos relativos a su autogobierno como son los siguientes: la determinación del régimen de la lengua oficial propia (art. $3.2 \mathrm{CE}$ ); el reconocimiento de enseñas y banderas propias (art. 4.2 CE); el régimen de su financiación que se justifica en la medida en que la Comunidad Autónoma dispone de competencia para establecer y exigir tributos propios (art. 133.2 CE) junto a la posibilidad de actuar como colaboradora o delegada del Estado para la recaudación, gestión y liquidación de sus recursos tributarios (art. 156.2 CE); la determinación de los casos, requisitos y plazos para la celebración de convenios y acuerdos de cooperación con otras Comunidades Autónomas (art. 145 CE); las formas de participación en la organización de las demarcaciones judiciales de su territorio (art. 152.1 CE); y, finalmente, la creación y el reconocimiento de circunscripciones territoriales propias, constituidas a partir de la agrupación de municipios (art. 152.3 CE).

Y un tercer ámbito para el contenido del Estatuto lo conforman aquellas materias propias del autogobierno que son un contenido también adicional o posible, en la medida en que su inclusión sea un complemento o una definición más precisa del alcance del contenido necesario que los Estatutos han de tener. En este contexto se han de incluir el Título I dedicado al reconocimiento de los derechos, deberes y principios estatutarios. Se trata de una previsión contenida en el Estatuto catalán que ha de merecer especial atención, a fin de justificar la constitucionalidad de esta opción del legislador estatutario.

\section{El derecho comparado ofrece ejemplos similares}

En efecto, en primer lugar, es preciso señalar que en los Estados políticamente descentralizados, con independencia de la forma que estos hayan adoptado (ya sea el clásico de Estado federal o de Estado regional que cuyos entes subestatales disponen de autonomía política), no es inhabitual que las Constituciones o los Estatutos regionales contemplen como parte integrante de su cuerpo dispositivo, una carta o declaración propia de derechos y principios a los que se ha de sujetar la acción de los poderes públicos. Por tanto, la previsión de esta declaración por parte el Estatu- 
to de 2006 no es una excepción en los ejemplos que aporta al respecto el derecho comparado, en los casos de estados compuestos. En este sentido, son diversos los antecedentes que se pueden invocar de entes subestatales (estados miembros, länder, cantones) integrados en estados políticamente descentralizados, que disponen de una declaración propia de derechos, además de la que reconoce la Constitución del Estado del que forman parte. Este es el caso, entre otros, de los estados miembros de los Estados Unidos, de los Cantones de Suiza, de algunos länder en la República Federal de Alemania, de algunas Regiones de la República italiana, como es el reciente caso que ofrece el Estatuto de la Región de la Toscana, además de la Umbría y la Emilia Romagna, siendo en estas dos últimas en las que el estatuto regional ha establecido previsiones respecto de los derechos de los inmigrantes, cuestión que ha suscitado el pronunciamiento de la Corte Constitucional en sus sentencias de 2004 (372; 378 y 379) en un sentido, ciertamente, poco favorable a su exigibilidad jurídica. Y en el constitucionalismo latinoamericano, cabe citar el caso de algunas de las Provincias de la República Argentina, como es el caso de la capital federal, la Ciudad Autónoma de Buenos Aires, o el de las Provincias de Catamarca, Córdoba o Jujuy.

En esta heterogeneidad de ejemplos, que responden a realidades históricas y constitucionales diversas, la singularidad que ofrecen las constituciones o normas institucionales de los entes subestatales respecto de las previsiones contenidas en la Constitución del Estado es variada, como lo es también el alcance y la relevancia de los derechos reconocidos por las constituciones o las normas de länders, estados, cantones, provincias o regiones. Pero en todo caso, parece obvio que de los ejemplos que ofrece el Derecho comparado no se deriva que el reconocimiento de una carta o tabla de derechos propia por los entes subestatales sea únicamente una característica propia de los Estados descentralizados de carácter federal.

\section{El reconocimiento de una declaración de derechos es un límite y, a la vez, un impulso a la acción de los poderes públicos}

La inclusión de un título en el que se contiene una declaración propia de derechos y deberes es una forma de limitar el poder público, sin perjuicio de lo que con la misma finalidad ha previsto la Constitución española de 1978, en su Título I. Además, la incorporación del amplio y prolijo catálogo de principios rectores, es una forma de institucionalizar unos criterios generales que han de operar como un impulso a los poderes públicos para el desarrollo de políticas públicas en el ámbito de sus competencias.

En segundo lugar, esta previsión de un título dedicado a determinar los derechos, deberes y principios no contradice el ordenamiento constitucional vigente. En efecto, hay que precisar que, de acuerdo con lo que prevé el título I de la CE, los ciudadanos de Cataluña son titulares de los 
derechos y libertades allí reconocidos con independencia de lo que establezca el Estatuto de autonomía. Al igual que en otros Estados compuestos, el Título I es una concreción o especificación del contenido de derechos ya existentes y reconocidos por la Constitución, sin perjuicio de incorporar otros de nueva formulación, aunque su matriz se encuentre ya recogida en los derechos y libertades garantizados por la CE.

La opción de la reforma estatutaria en su Título I se enmarca en las aportaciones de constitucionalismo comparado, en el que la descentralización de la autonomía política ha permitido que las declaraciones de derechos y libertades de los entes subestatales, incorporan a sus textos constitucionales o estatutarios cartas de derechos, deberes y principios como una forma de expresión de identidad política. De esta forma, y asumiendo la superior garantía que la Constitución de la Federación o del Estado ofrece para los derechos y libertades de los ciudadanos, la norma institucional del ente subestatal (Länder, Estado, Provincia, Comunidad Autónoma o Región) especifica y desarrolla el contenido de los derechos y libertades preexistentes, pero también añade otros de carácter emergente que son fruto, tanto de la evolución social como de las transformaciones operadas en las relaciones entre los poderes públicos y los ciudadanos, en las formas democráticas de gobierno democrático, en las que la Administración pública constituye un nuevo Leviathan frente al que se hace preciso articular nuevos controles y tutelas a fin de garantizar el principio de libertad. Y, por supuesto, en las nuevas incorporaciones de derechos no pueden olvidarse las aportaciones procedentes de otras Declaraciones de derechos contenidas en Constituciones estatales o en textos de Derecho Constitucional supraestatal, como por ejemplo es el caso de la Carta de Derechos Fundamentales de la Unión Europea proclamada en Niza en 2000 y que en la actualidad opera como parámetro interpretativo para el derecho vigente. Todo lo cual pone de relieve que la garantía de los derechos y libertades se expresa a través de diversos niveles institucionales, en los que sin perjuicio de la hegemonía del Estado o de la Federación, estos ya no ostentan la exclusividad en la formulación y reconocimiento de los derechos y libertades de los ciudadanos.

En una norma institucional básica, como son los Estatutos de autonomía, es decir, en una norma de naturaleza subconstitucional, es preciso señalar que los derechos y libertades, desarrollan una función plenamente constitucional en el territorio dotado de autogobierno en el que se aplican. Una función constitucional que no es nueva sino que se adentra en la teoría clásica de la Constitución. A saber: los derechos y libertades, como límite a la acción del poder público, conjuntamente con el principio de la división de poderes, forman parte de las señas de identidad del Estado de derecho y del constitucionalismo racional normativo, como así lo puso de manifiesto el artículo 16 de la célebre Declaración francesa de Derechos del Hombre y del Ciudadano de 1789, incorporada en la Constitución de 
la V República francesa de 1958. La CE de 1978, así como la mayoría de las que se promulgaron después de 1945, son herederas de esta tradición constitucional.

La incorporación de un título dedicado a derechos, deberes y principios en Estatuto es una opción legítima desde la óptica constitucional por dos razones fundamentales. La primera, porque el Estatuto -hay que reiterarlo- como norma institucional básica de Cataluña (art. 147.1 CE), y también como norma del Estado derivada de la Constitución, concreta el derecho a la autonomía política. Por su parte, los órganos de la Generalidad, como institución de autogobierno, y el resto de los poderes públicos en Cataluña, ejercen las funciones que el Estatuto les ha encomendado para llevar a cabo las políticas públicas que estimen pertinentes, de acuerdo con la legitimidad que les da la representación política obtenida en las elecciones, en el marco de las competencias que el Estatuto, como norma subconstitucional, ha establecido. En este sentido, es un principio esencial del constitucionalismo democrático que la actividad de los poderes públicos está sometida a límites, y las declaraciones de derechos y libertades son la manifestación principal de estos límites, tanto frente a los poderes públicos como también con respecto a las acciones de los particulares (art. 9.1 CE). Por lo tanto, el límite a la acción de los poderes públicos y, en su caso, el impulso a fin de que estos tengan unos parámetros a seguir en el desarrollo de sus políticas públicas, es una lógica consecuencia de alcance constitucional que el Estatuto debe establecer, y la previsión de un título que determine derechos, deberes y principios es una opción que goza de plena cobertura constitucional.

La incorporación, pues, de una Declaración de derechos y libertades en es, en esencia, una específica expresión de autogobierno pero no significa aumento del autogobierno. Es decir, con la incorporación del Título I el legislador estatutario expresa su autonomía política para establecer unos límites y configurar unos principios de actuación de los poderes públicos, que en unos casos -la mayoría- son los propios de la Comunidad Autónoma y en algunos otros, los destinatarios son también los poderes públicos del Estado que actúan en el ámbito en el ámbito de aquella si se trata de una materia competencial que corresponda a la Generalitat. La Declaración o Carta de derechos es expresión de autogobierno en la medida que el legislador del Estatuto manifiesta su voluntad de limitar el ejercicio de las competencias de acuerdo con unos valores y principios, que han de gozar de apoyo constitucional, a fin de garantizar los derechos de los ciudadanos. Y con la misma finalidad, la incorporación del amplio listado de principios rectores - sin duda, muy prolijo, excesivo y retórico- ha de ser entendido como un impulso para el desarrollo de un programa normativo que el legislador, de acuerdo con el valor indeclinable del pluralismo político, habrá de concretar. En este sentido, pues, los derechos, deberes y principios, en su condición de límite al poder público que viene impuesto 
por el Estatuto (de acuerdo, claro está, con la Constitución) son una expresión del autogobierno y de la dimensión materialmente constitucional del Estatuto.

\section{El reconocimiento de una declaración de derechos está vincula- da a las competencias}

Los derechos, deberes y principios incorporados a la Propuesta de reforma no obedecen a un acto de voluntarismo jurídico. Su inclusión responde, en este sentido, a un criterio bien preciso: su relación con el contenido de las competencias que vienen definidas en el Estatuto. Así lo puso también de relieve, en su Dictamen de 1 de septiembre de 2005 el Consell Consultivo de la Generalitat.

En efecto, en la medida que su título IV del Estatuto, de acuerdo con la Constitución (art. 147.2.d CE), ha determinado las competencias con una especial voluntad de concreción, tanto en lo que concierne a los aspectos materiales como en lo relativo a los funcionales, es una consecuencia lógica que también se concreten tanto los derechos y deberes que operan como límites e impulso al ejercicio de estas competencias y también los principios que ha de informar la acción futura del legislador autonómico. Al fin y al cabo, la previsión de un título que, además de lo que prevé el título I de la CE, consagre de forma específica una serie de derechos y principios a los que queda sometida la actividad de los poderes públicos y de los particulares en Cataluña, es un contenido adicional que el Estatuto puede tener sin contravenir ni violentar, las previsiones constitucionales sobre lo que los Estatutos de autonomía pueden prever (art. 147.2 CE).

\section{La Declaración de derechos respeta los límites constitucionales}

El Estatuto respeta tres prescripciones constitucionales ineludibles. La primera es el respeto a la reserva de ley orgánica en lo que se refiere al desarrollo directo de los derechos fundamentales y libertades públicas de la Sección $1^{\mathrm{a}}$ del Capítulo II del Título I de la CE (art. $81 \mathrm{CE}$ ), una reserva que el Estatuto a pesar de su carácter orgánico no puede satisfacer y al que la Propuesta se atiene; la segunda, es la relativa a la sujeción a las condiciones básicas que el Estado haya establecido para garantizar a todos los españoles la igualdad en el ejercicio de los derechos y en cumplimiento de los deberes constitucionales (art. 149.1.1 CE); y la tercera es la que se deriva de la propia naturaleza jurídica del Estatuto, en su condición de norma institucional básica, lo cual significa que se trata de una norma dirigida de forma primordial a orientar y al mismo tiempo limitar los poderes públicos de Cataluña y, en el marco de sus competencias, a los entes locales del mismo ámbito territorial. Aún así, y atendiendo a su condición -también- de norma estatal, no debe excluirse que el Estatuto, al vincular 
los poderes públicos de Cataluña, pueda incidir simultáneamente sobre el ejercicio de competencias estatales. En su formulación final, resultante del texto aprobado en las Cortes Generales, ello se pone de manifiesto en el artículo 37.1 del Estatuto, en relación con los derechos y deberes de conocimiento y uso de las lenguas y los derechos lingüísticos ante las Administraciones públicas y las instituciones estatales.

\section{La organización de las garantías de los derechos estatutarios: es- pecial referencia al Consejo de Garantías Estatutarias}

El artículo 38.1 del Estatuto establece lo siguiente: "Los derechos reconocidos por los capítulos I, II y III del presente título y por la carta de los derechos $y$ deberes de los ciudadanos de Cataluña son tutelados por Consejo de Garantías Estatutarias, de acuerdo con lo establecido por el artículo 76.2 b) y c)”. En este último precepto se establece que: El Consejo de Garantías Estatutarias puede dictaminar, en los términos que establezca la ley, en los casos siguientes (...) b) La adecuación al presente Estatuto y a la Constitución de los proyectos y las proposiciones de ley sometidos a debate y aprobación del Parlamento y los Decretos leyes sometidos a convalidación del Parlamento; c) La adecuación al presente Estatuto y a la Constitución de los proyectos de Decreto Legislativo aprobados por el Gobierno". Finalmente -y aquí radica la novedad más relevante para las funciones de este órgano estatutario-, el apartado 4 del artículo 76 determina que: Los dictámenes del Consejo de Garantías Estatutarias tienen carácter vinculante con relación a los proyectos de ley y las proposiciones del Parlamento que desarrollen o afecten a derechos reconocidos por el presente Estatuto".

La atribución de esta función de tutela sobre los derechos estatutarios al nuevo Consejo de Garantías Estatutarias justifica el cambio de denominación que ha de tener en el futuro este órgano. Las razones son las siguientes: $1^{a}$ ) Sin duda, el carácter vinculante del dictamen del Consejo de Garantías Estatutarias "con relación a los proyectos de ley y las proposiciones de ley del Parlamento que desarrollen a afecten a derechos..." supone un cambio parcial en la naturaleza jurídica de las funciones de orden consultivo que hasta han caracterizado el estatuto jurídico y la labor del actual Consejo Consultivo. Puesto que en materia -únicamente- de derechos estatutarios, al vincular el dictamen al Parlamento, la función deja de ser consultiva para adoptar un carácter que bien podría catalogarse como cuasi jurisdiccional. En efecto, la Cámara legislativa deberá atenerse al sentido del dictamen sin posibilidad de hacer abstracción o prescindir de su contenido, sino que, en caso de una declaración explícita de inconstitucionalidad deberá incorporar al proyecto o proposición, la decisión del Consejo de Garantías Estatutarias, salvo que una vez conocido el dictamen el proyecto o proposición legislativos sean retirados por sus proponentes. De esta forma, con esta participación previa en el proceso de elaboración de la ley autonómica, el Consejo adopta una posición institucional asimilable a la 
que en la actualidad ostenta el sistema constitucional francés, el Conseil Constitutionnel.

$\left.2^{a}\right)$ Este dictamen vinculante no pone en cuestión el monopolio del control de constitucionalidad de la ley que corresponde realizar al Tribunal Constitucional. Es evidente, la interpretación constitucional es una función que se encuentra diseminada entre los diversos operadores jurídicos, sean estos de carácter jurisdiccional o no. Uno de ellos, desde luego, son los Consejos Consultivos de las Comunidades Autónomas y, de forma singularmente especial, también lo será el nuevo Consejo de Garantías Estatutarias. En este contexto de participación en la interpretación constitucional de las normas con rango de ley, el Consejo y las funciones que le han sido atribuidas en materia de derechos estatutarios, son una expresión de la autonomía institucional de la Generalitat, por la que dispone de capacidad de decisión, de acuerdo con la Constitución, para la organización de sus instituciones. Es decir, con su función definida por el Estatuto de tutela previa de los derechos, está ejerciendo una función de autocontrol participando en el proceso de elaboración de la ley que, sin embargo, en ningún caso cuestiona ni suplanta el control a posteriori, sobre la ley autonómica, una vez incorporada al ordenamiento jurídico tras la aprobación por el Parlamento de Catalunya.

$\left.3^{a}\right)$ En este sentido, la ley autonómica que, en su caso, sea juzgada por el Tribunal Constitucional, será lógicamente aquella que haya sido aprobada por el Parlamento de Cataluña, de acuerdo - si para ello ha sido requerido previamente- con el dictamen vinculante del Consejo de Garantías Estatutarias. En consecuencia, esta ley autonómica siempre será el resultado del ejercicio de la potestad legislativa de la que es titular el Parlamento, el que deberá asumir el dictamen del Consejo o, de no hacerlo, instar al Gobierno a retirar su proyecto o bien, si se trata de una proposición de ley, hacer lo propio y no ejercer la potestad de legislar con el texto censurado por le Consejo de Garantías Estatutarias.

Por tanto, la ley resultante tras un dictamen del Consejo no de una confluencia de voluntades entre el Parlamento y el Consejo de Garantías Estatutarias. La intervención previa de este, que puede conllevar la modificación del texto aprobado por la institución legislativa, queda legitimada por disposición del Estatuto como norma institucional básica. Ciertamente, la controversia que sin duda pueda suscitar en este caso la relación entre la voluntad del órgano legislativo y la opinión de un colegio de juristas nos ubica en un contexto similar al que en el Estado social y democrático de derecho, experimenta la relación entre democracia y justicia constitucional.

$4^{\mathrm{a}}$ ) El objeto del dictamen son los proyectos y proposiciones de ley del Parlamento que desarrollen o afecten a derechos reconocidos en el Estatuto. Esta formulación presenta problemas de interpretación. En primer lugar, porque asimila dos conceptos que son distintos; “(...) desarrollen o 
afecten (...)". "Desarrollar" es más preciso que "afectar", que razonablemente hay que deducir que es un concepto de contenido más genérico. En términos jurídicos, "desarrollar" un derecho comporta la regulación de los elementos básicos de su régimen jurídico (aspectos relativos a titularidad, objeto, forma de ejercicio, etc.) mientras que "afectar" es una noción más amplia en la medida en que ha de servir para detectar la incidencia de una disposición normativa sobre el contenido general del derecho. Entiendo, que en este sentido el precepto puede generar una notable confusión que, a buen seguro, exigirá un esfuerzo interpretativo sobre el alcance de esta importante función del Consejo de Garantías Estatutarias. Probablemente, pueda servir, en este sentido de referente para este objetivo los criterios empleados por el Tribunal Constitucional acerca de los límites materiales que operan sobre el decreto-ley cuando este pueda afectar a los derechos, deberes y libertades, contenidos en la célebre STC 111/1983, de 2 de diciembre.

\section{LA COMPETENCIAS PARA EL EJERCICIO DEL AUTOGOBIERNO}

\section{Una consideración previa: la relación entre ley básica estatal y ley de desarrollo autonómica}

La relación entre ambas fuentes del ordenamiento es la cuestión central del sistema de distribución de competencias entre el Estado y las CCAA. Para evaluar la constitucionalidad de ambas normas a la CE, el TC ha empleado como necesario parámetro el concepto de bloque de la constitucionalidad, integrado por el binomio que forman la CE y el Estatuto.

La sentencia de mayor relieve del Tribunal Constitucional en el período inicial de construcción de la autonomía política, fue la STC 76/1983, que resolvió diversos recursos de inconstitucionalidad presentados contra el proyecto de ley orgánica de armonización del proceso autonómico (LOAPA). Esta sentencia frenó una iniciativa política destinada a limitar considerablemente el alcance del autogobierno. A grandes rasgos, la STC 76/1983 abordó la relación entre poder constituyente y poder constituido y subrayó las limitaciones de la potestad legislativa del Estado. Sobre este particular, el TC reconoció que las Cortes Generales, en su condición de titulares de la potestad legislativa del Estado, pueden legislar, en principio, sobre cualquier materia sin disponer de título específico, pero esta potestad está sometida a las limitaciones derivadas de la Constitución. En este sentido, lo que está impedido a las Cortes es ocupar el lugar del legislador constituyente desarrollando actos que son propios de este, salvo cuando lo establezca la propia Constitución. Teniendo en cuenta las previsiones establecidas en el Proyecto de LOAPA, las consecuencias de esta doctrina jurisprudencial fueron las siguientes: 1) El legislador estatal no puede 
dictar normas que incidan en el sistema constitucional de distribución de competencias, integrando hipotéticas lagunas existentes en la Constitución; 2) este mismo legislador no puede incidir con carácter general en el sistema de delimitación de competencias establecido por los artículos 147 a 149 de la CE y en los Estatutos respectivos, sin una expresa previsión constitucional (por ejemplo, la contemplada en los arts. 150.2 y $3 \mathrm{CE}$, para delegar o transferir y para armonizar competencias), razón por la cual una parte de los artículos del proyecto de LOAPA eran inconstitucionales; 3) el legislador ordinario no puede dictar normas meramente interpretativas que tengan como objeto precisar un único sentido, entre otros posibles, que haya que atribuir a una norma, porque esta manera de actuar del legislador ordinario como poder constituido se sitúa impropiamente en el lugar del legislador constituyente.

Además de la sentencia sobre la LOAPA, la jurisprudencia sobre la legislación básica estatal fue uno de los aspectos jurídicos de mayor relieve durante el primer periodo del autogobierno de las CCAA en España. El abuso de la utilización de la normativa preconstitucional para fijar las bases en los diversos ámbitos materiales y el tiempo de vigencia de la CE de 1978, aconsejaron la fijación de unos criterios formales que el Estado había de tener en cuenta a la hora de aprobar su normativa básica. Las SSTC $69 / 1988$ y $80 / 1988$ fueron una oportunidad para frenar los abusos que el Estado reiteradamente llevaba a cabo, estableciendo para ello la noción de norma básica y el concepto material y formal de bases. Esta doctrina habría de servir en el futuro para objetivar los criterios de relación entre la ley básica estatal y la ley autonómica de desarrollo.

De acuerdo con esta jurisprudencia, las normas básicas estatales no pueden ser una vía de distribución de competencias. Han de tener por objeto delimitar con carácter general el espacio normativo al cual se han de adecuar las CCAA. Son un mínimo común denominador normativo que corresponde fijar al legislador estatal, sin alterar el orden constitucional y estatutario de distribución de competencias y con la debida garantía del principio de seguridad jurídica. Con estos presupuestos, la función de defensa del sistema de distribución de competencias ha de venir orientada a asegurar dos finalidades esenciales: 1) procurar que la definición de lo básico no quede a la libre disposición del Estado, a fin de evitar que las competencias autonómicas puedan ser restringidas; 2) velar porque el cierre del sistema competencial no se mantenga en una nebulosa permanente y ambigua, a fin de evitar que el Estado disponga siempre de la facultad omnímoda de atribuir a cualquier precepto legal o reglamentario la condición de norma básica.

A fin de satisfacer la primera de estas finalidades, el TC ya estableció con anterioridad el concepto material de ley básica, según el cual es preciso entender que la definición de lo básico por el legislador estatal no comporta que se haya de aceptar de forma incondicional e indubitada; todo lo 
contrario, la norma a la cual se le ha atribuido el carácter de básica puede ser impugnada y la determinación de dicho carácter corresponde siempre al TC, en su condición de intérprete supremo de la CE. Y para dar cumplimiento a la segunda finalidad, se establece el principio de ley formal, que comporta que ha de ser una ley de las Cortes Generales el instrumento habitual por el cual se atribuya a un precepto la condición de básico. No obstante, y como excepción a este principio general de ley formal, el Gobierno del Estado puede regular por decreto algunos de los aspectos básicos de la materia competencial, siempre que resulten, en virtud de la propia naturaleza de esta, un complemento necesario para garantizar la finalidad a la cual responde la competencia estatal sobre las bases.

Esta fue, pues, la doctrina del TC sobre el carácter de legislación básica estatal. Sin embargo, el grado de vinculación que los diversos legisladores han mostrado respecto al principio formal ha sido muy relativo: en efecto, el abuso del reglamento administrativo como instrumento para determinar el mínimo común denominador ha sido y es un hecho contrastado, hasta el punto de haberse utilizado, incluso, la Circular como vía a estos efectos. La consecuencia ha sido que la normativa básica estatal ha mostrado un contenido enormemente detallado y concreto, muy alejado de las bases entendidas como grandes principios a los que había de adaptarse la ley autonómica. Hasta ahora, esto ha sido así, razón por la cual el legislador autonómico ha dispuesto de un margen de maniobra normativo muy reducido, lo cual ha dado lugar a que, por ejemplo, en materias competenciales tan significativas - por poner un ejemplo- como la regulación de la administración local o la enseñanza, la legislación autonómica ha sido una simple reiteración de la estatal, técnica legislativa especialmente censurada por el TC por la inseguridad jurídica que puede generar ${ }^{11}$.

\section{El significado competencial del nuevo Estatuto de 2006}

La utilización expansiva de la legislación básica por el Estado ha comportado una reducción de la autonomía normativa de la CCAA. En Catalunya y también en el País Vasco, esta circunstancia ha producido una notable insatisfacción, lo que en el caso catalán ha conducido a la reforma estatutaria, ante la imposibilidad política de reformar la Constitución ${ }^{12}$,

Acerca del debate sobre el alcance de la legislación básica estatal, la bibliografía es abundante. A modo de síntesis, consúltese: Jiménez Campo, J. (1989) "Qué es lo básico? Legislación compartida en el estado autonómico". REDC No 27; Albertí Rovira, E. (1991) "La noción de bases y el desarrollo estatutario". Estudios sobre el Estatuto de Autonomía del País Vasco". II. Oñati: IVAP; BAyona Rocamora, A. (1992) El derecho a legislar en el Estado autonómico. Madrid: Tecnos/Escola d'Administració Pública.

12 El grado de esta insatisfacción puede medirse por el hecho de que la Generalitat de Catalunya ha sido la Comunidad Autónoma que, por término medio, ha planteado más contenciosos competenciales ante el Tribunal Constitucional. Para un conocimiento detallado de esta con- 
una solución que habría de permitir en el futuro una clarificación acerca del alcance de la legislación básica estatal.

Desde luego, esta circunstancia no impide reconocer el importante nivel de autogobierno establecido tras veintiocho años de autonomía política. Las Comunidades Autónomas gestionan en la actualidad un $40 \%$ de gasto público y disponen de más del $50 \%$ del personal al servicio de las administraciones públicas. No hay duda que la restauración de la democracia supuso para Cataluña la recuperación de sus instituciones de autogobierno, pero en lo que se refiere a la autonomía normativa, es decir, la potestad - a partir de unos bases o principios comunes- de legislar de forma distinta, ha dado como resultado un autogobierno de baja calidad.

El Título IV del nuevo Estatuto de 2006 regula las competencias de la Generalitat de acuerdo con las previsiones establecidas en los artículos del Título VIII y, en especial los artículos 148, 149.1 y 150 de la CE. En relación al citado Título VIII, hay un acuerdo mayoritario en la doctrina española en considerar que su contenido es muy abierto y, de hecho, desconstitucionalizado.

La pregunta que cabe hacerse es, si una reforma de Estatuto como la pretendida por el Parlamento de Cataluña puede llevarse a cabo y más concretamente, si invade competencias reservadas al Estado para determinar qué es lo básico. Con esta voluntad de delimitar materialmente los actuales títulos competenciales, ¿la reforma estatutaria estaría asumiendo una función constituyente?, ¿estaría el Estatuto definiendo lo básico? Un sector de la doctrina española considera que, en efecto, la reforma estatutaria supone una suplantación de la posición del legislador básico estatal. En este sentido, se sostiene que, con la precisión funcional y material de las competencias se está hurtando a las Cortes Generales de la función de determinar el alcance de la legislación básica ${ }^{13}$.

Sin embargo, partiendo de la desconstitucionalización aludida, no parece que hayan razones jurídicas substantivas que permitan sostener que una reforma estatutaria como la descrita esté suplantando al Estado en su competencia para fijar lo básico. El carácter genérico que presenta la Constitución en la determinación de los títulos competenciales hace que, salvo alguna excepción expresamente contenida en la $\mathrm{CE}$, no existe una reserva en favor de ley estatal para concretar los criterios de carácter funcional y

flictividad veáse: M.CARrillo, de forma individual y en colaboración, según los años, con L.J. Mieres, H. López Bofill y R. Riu, "Tramitación de conflictos de competencias ante el Tribunal Constitucional", contenidos anualmente en el Informe Comunidades Autónomas. Barcelona: Instituto de Derecho Público, 1992-2005.

13 Ortega Álvarez, L. (2005) La redefinición por los estatutos de autonomía de la distribución territorial del poder contemplado en la constitución. Madrid: Ministerio de Administraciones Públicas. De la Quadra-Salcedo Janini, T. (2004) "¿Es el Estatuto de Autonomía una norma capaz de modular el alcance de la legislación básica del Estado?". Revista Española de Derecho Constitucional, No 70, pp. 135-161. 
material establecidos en la Constitución para delimitar las competencias. Por otra parte, tampoco de la Constitución cabe derivar un mandato ineludible por el que la delimitación de competencias deba quedar abierta. Es decir, tampoco existe una reserva de Constitución en este sentido. Por otra parte, de acuerdo con lo que preceptúa la Constitución en su artículo 147.2. d), los Estatutos de Autonomía, en su condición de norma institucional básica de cada Comunidad Autónoma, deberán contener las competencias asumidas dentro del marco establecido en la Constitución. Por tanto, no hay razón para que el Estatuto no pueda realizar esa función de concreción material y funcional de sus competencias respecto de las materias que actualmente la Constitución le permite asumir. Es una vía que, por otra parte, y como consecuencia de esta concreción, ha de proporcionar una mayor seguridad jurídica al sistema de distribución de competencias que tanto se ha encontrado a faltar hasta ahora. Ha de garantizar una autonomía más plena, ciertamente, en un contexto en el que la lógica que hasta ahora ha presidido la legislación básica estatal demanda un punto de inflexión, a fin de que las bases a las que se refiere el artículo 149.1 CE, para ser un verdadero mínimo común denominador, respondan a la lógica de los grandes principios ${ }^{14}$.

De acuerdo con lo establecido en los artículos 110 a 115 del Estatuto de 2006 (EAC), la tipología de competencias se estructura de la siguiente forma: exclusivas, compartidas y ejecutivas. En las materias donde se dispone de competencias exclusivas, la Generalitat ejerce de manera íntegra, la potestad legislativa, la potestad reglamentaria y la función ejecutiva (art, $110 \mathrm{EAC}$ ). En las competencias compartidas con el Estado, la Generalidad dispone de la potestad legislativa, la potestad reglamentaria y la función ejecutiva, en el marco de las bases que fije el Estado (art. 149.1. $\mathrm{CE}$ ), entendidas estas como principios o mínimo común normativo a través de normas con rango de ley, excepto en los supuestos que se determine de acuerdo con la Constitución y el Estatuto (art. 111 EAC). Por lo que se refiere a la competencias ejecutivas, la Generalidad dispone de la potestad reglamentaria para la ejecución de la normativa de Estado y también la función ejecutiva, que en todo caso incluye la potestad de organización de su propia administración y, en general, todas las funciones y actividades que el ordenamiento atribuye a la Administración pública (art. 112 EAC).

Albertí, E. (2005): "El blindatge de les competències i la reforma estatutària". Revista Catalana de Dret Públic, N 31, pp. 109-136; Viver PI-Sunyer, C. (2005) "La reforma de los Estatutos de Autonomía" a La reforma de los Estatutos de Autonomía. Con especial referencia al caso de Cataluña. Madrid: Centro de Estudios Políticos y Constitucionales; Carrillo, M. (2005) "La delimitación de competencias, entre la Constitución y jurisprudencia constitucional: ¿qué puede hacer el Estatuto? En Pérez Tremps, P. Coordinador (2005) La reforma de los Estatutos de Autonomía. IV Congreso de la Asociación de Constitucionalistas de España. Valencia: Tirant lo Blanch, pp. 417-436. 
Por otra parte, en el marco de estas competencias, corresponde a la Generalidad el despliegue, la aplicación y la ejecución de la normativa de la Unión Europea (art. 113 EAC). Y, finalmente, la regulación del nivel de intervención en la actividad de fomento llevada a cabo por la Generalidad, queda modulada de forma directamente proporcional a la naturaleza de la competencia materia de que se dispone (art. $114 \mathrm{EAC}$ ).

\section{LAS RELACIONES CON EL ESTADo Y LA UNión EUROPEa}

El nuevo Estatuto incorpora una novedad de especial relevancia en el Título V. Es la relativa a la regulación de las relaciones institucionales de la Generalitat. Se entiende por tales, en primer lugar, las relaciones con el Estado y otras CCAA; en segundo lugar, las relaciones con la Unión Europea y, finalmente, la acción exterior de la Generalitat.

Se hace preciso señalar que una buena parte de las previsiones de este Título $\mathrm{V}$ ya forman parte de la práctica institucional de los últimos años avalada por la jurisprudencia del Tribunal Constitucional. Pero además, el Estatuto avanza en la línea de incorporar a su contenido elementos propios de la integración Europea, en la medida en que España como Estado compuesto que es parte integrante de la Unión, se ha visto afectada por el proceso de la construcción institucional de Europa. Tanto en el sentido descendente, de la integración del ordenamiento europeo en el derecho español (el del Estado y el de Catalunya) como en el sentido ascendente, de la participación del Estado (y en su seno, las CCAA, entre Catalunya) en las instituciones del la Unión ${ }^{15}$.

\section{Relaciones de la Generalidad con el Estado y otras CCAA (arts.174-183 EAC)}

El Estatuto regula los instrumentos de colaboración y sus efectos. Se trata de las vías típicas de colaboración de los Estados compuestos, en especial los convenios tanto de carácter bilateral como de naturaleza multilateral. Ya sea de convenios en sentido vertical, con el Estado, o los convenios en sentido horizontal, con el resto de las CCAA. En este aspecto, lo que el Estatuto ha previsto no es otra cosa que la cristalización normativa de una práctica desarrollada a lo largo de los años de autogobierno, especialmente en el primer caso pero mucho menos en el segundo.

No obstante, en este capítulo, el Estatuto introduce como novedad la creación de una Comisión Bilateral Generalitat-Estado, como ámbito 
orgánico de relación entre los gobiernos de la Generalitat y del Estado. Y, en especial introduce unas muy genéricas previsiones acerca de las formas de participación de la Generalidad en las instituciones y procedimientos de decisiones que corresponden al Estado. Son las siguientes: la comparecencia ante el Parlamento autónomo, de los senadores elegidos en Catalunya o que representen a la Generalitat en el Senado; la designación de miembros del Tribunal Constitucional y del Consejo General del Poder Judicial; la participación en la ordenación general de la actividad económica; la designación de representantes en los organismos económicos y sociales. En todos estos casos, en la medida que se trata de competencias de titularidad estatal, el Estatuto se remite a lo que la ley del Estado establezca al respecto. Por esta razón, se trata de preceptos jurídicos cuya eficacia jurídica queda diferida a la decisión que el legislador estatal pueda tomar en relación al régimen de un órgano constitucional que solo al Estado compete regular. Pero el Estatuto no se inmiscuye sino que establece un principio de participación Autonómica, siempre subordinado a la decisión estatal. La constitucionalidad del precepto no ofrece dudas como tampoco las presenta, por sí solo, su nula eficacia jurídica. No obstante, las reciente reforma de la Ley Orgánica del Tribunal Constitucional, en coherencia con el principio establecido en el Estatuto catalán establece una regulación que debe permitir que las CCAA en su conjunto, pueda participar a través del Senado, en la propuesta de magistrados para el Tribunal Constitucional.

\section{Relaciones de la Generalitat con la Unión Europea (arts. 184- 192 EAC)}

También aquí, el Estatuto establece una regla general de eficacia diferida a la interpositio legislatoris estatal. Los términos son los siguientes: "La Generalitat participa, en los términos que establecen este Estatuto y la legislación del Estado, en los asuntos relacionados con la Unión Europea que afecten a las competencias o a los intereses de Catalunya". De acuerdo, pues, con ello el Estatuto establece un principio genérico acerca de la participación de la Generalitat en la revisión de los Tratados de la Unión (a través del deber de ser informada); en la formación de la posición del Estado ante la Unión; la participación en las delegaciones españolas ante la Unión; en el control de los principios de subsidiariedad y proporcionalidad; en el desarrollo y aplicación del derecho de la Unión; en la gestión de los fondos europeos y en las acciones judiciales ante el Tribunal de Justicia de la Unión, en los términos que la normativa europea establezca al respecto. Finalmente, el Estatuto también incorpora una realidad organizativa ya preexistente: la Generalitat puede establecer una delegación para defender sus intereses ante las instituciones de la Unión. 


\section{La acción exterior (arts. 193-200 EAC)}

De acuerdo con la consolidada jurisprudencia del TC que distingue entre relaciones internacionales (competencia exclusiva del Estado) y acción exterior de los entes subestatales (CCAA) ${ }^{16}$, el Estatuto establece que la Generalitat tiene capacidad para llevar a cabo acciones con proyección exterior que deriven directamente de sus competencias, bien de forma directa o por medio de los órganos de la Administración del Estado. Con este fin, puede abrir Oficinas en el exterior; suscribir Acuerdos de colaboración en el ámbito de sus competencias; ser informada previamente sobre los actos de suscripción de tratados que afecten de manera directa y singular a las competencias de Catalunya; promover la cooperación con las regiones europeas con las que comparte intereses económicos, sociales, ambientales y culturales (de hecho, ello viene siendo así con la región francesa del Languedoc-Rousillon y la italiana de la Lombardía) y la participación en organismos internacionales, como es el caso de la UNESCO, en la forma que establezca la legislación correspondiente (estatal e internacional).

\section{El SISTEMA DE FINANCIACIÓN}

El sistema de financiación de las CCAA en España se basa en dos sistemas diferenciados. El primero, es el general y queda regulado de acuerdo con lo establecido en la CE, en los respectivos Estatutos de Autonomía y en una Ley específica prevista en el artículo 157.3 de la CE, la Ley Orgánica de Financiación de las CCAA (LOFCA), que ha quedado integrada en el ámbito material del bloque de constitucionalidad. El segundo, es el sistema especial previsto para las CCAA del País Vasco y Navarra, basado en el sistema de concierto y convenio respectivamente.

El sistema vigente en Cataluña ${ }^{17}$, pertenece al primer grupo, el de carácter general y la reforma estatutaria de 2006 no se aparta de dicho modelo.

De acuerdo con lo establecido en la reforma, los principales recursos financieros de la Generalitat están constituidos por: los rendimientos de sus impuestos, tasas, contribuciones especiales y otros tributos propios; por el rendimiento de todos los tributos estatales cedidos; los recargos sobre los tributos estatales; los ingresos procedentes del Fondo de Compensación Interterritorial, etc. Estos son las fuentes principales, en las que los

17 Bosch I Roca, N. (2006) "El model de finançament autonòmic del projecte de reforma de l'Estatut de Catalunya" a Revista Catalana de Dret Públic, No 32, pp. 15-35; Girón Reguera, E. (2007) "La incidencia de la reforma de los Estatutos de Autonomía en la financiación autonómica". REDC $\mathrm{N}^{\circ} 80$, pp. 75-111. 
rendimientos de los impuestos cedidos son la vía principal de financiación autonómica.

En el marco de las competencias del Estado y de la Unión Europea, la Generalitat dispone de capacidad normativa en materia tributaria que se traduce en: la fijación del tipo impositivo, las exenciones, las reducciones y las bonificaciones sobre la base imponible y las deducciones sobre la cuota.

Entre las innovaciones más relevantes introducidas por el nuevo Estatuto de 2006, destacan las siguientes:

- La creación de Agencia Tributaria catalana, por la que la Generalitat le corresponde la gestión, la recaudación, la liquidación y la inspección de todos los tributos propios; y, por delegación del Estado, también la de los tributos cedidos totalmente. Y, en régimen de colaboración con el Estado a través de un régimen consorcial, puede ejercer idénticas funciones respectos de lo impuestos cedidos parcialmente.

- Se establece una cláusula de inversiones estatales en infraestructuras, excluido el Fondo de Compensación, que se ha de equiparar a la participación relativa del producto nacional bruto de Catalunya en relación con el producto nacional bruto del Estado, por un período de 7 años. El carácter jurídicamente vinculante que pueda tener esta condición al ejercicio de la potestad presupuestaria de las Cortes Generales es cuestionado por una buena parte de la doctrina, que reconoce que esta cláusula cabe más bien entenderla en el contexto del acuerdo político.

- Se cede a la Generalitat el 50\% del Impuesto de la renta de las personas físicas.

- Se cede a la Generalitat el 58\% sobre impuestos especiales (hidrocarburos, alcohol, tabaco...)

- Se cede a la Generalitat el 50\% del Impuesto sobre el valor añadido.

A fin de que estas previsiones estatutarias encajen en el marco constitucional, es evidente que será precisa una reforma en el mismo sentido de la ley estatal del artículo 157.3 CE, la LOFCA.

\section{Bibliografía $^{18}$}

- L’estatut d'Autonomia de Catalunya de 2006. Edició a CàrRec de Marc Carrillo (2007). Textes Jurídics. Barcelona: Institut d'Estudis Autonòmics.

18 Se incluye aquí una amplia bibliografía sobre las reformas de los Estatutos de Autonomía llevadas a cabo hasta ahora en España, que puede resultar de interés para el lector del ámbito jurídico latinoamericano. 
- Tornos, J. (2007) Los Estatutos de Autonomía de Cataluña. Madrid: Iustel.

- AA. DD. (2004) Estudios sobre la reforma del Estatuto. Barcelona: Institut d'Estudis Autonòmics.

- _ _ (2005) Monográfico sobre La reforma de los Estatutos de Autonom a y reforma de la Constitución de la València: Revista Espanyola de la F inción Consultiva.

- Aleertí, E. (2005) "El blindatge de les competències i la reforma estatutària" Revista Catalana de Dret Públic, $\mathrm{N}^{\circ} 31$.

- Aparicio Pérez, M. A. (2005): "L'adequació de l'estructura de l'Estat a la Constitució (reforma constitucional vs. Reforma dels estatuts)" Revista Catalana de Dret Públic, $\mathrm{N}^{\circ} 31$.

- Aragón Reyes, M. (2006) "La construcción del Estado autonómico". Revista General de Derecho Constitucional. Iustel.

- Balaguer Callejón, F. (2005): "Comentario a "La reforma de los Estatutos de Autonomía" de Carles Viver i Pi-Sunyer". La reforma de los Estatutos de Autonomía. Con especial referencia al caso de Cataluña. Madrid: Centro de Estudios Políticos y Constitucionales.

(2005): Las reformas estatutarias desde la perspectiva de la ordenación competencial. Un análisis de las líneas generales del título $V$ de la Propuesta de Reforma del Estatuto de Autonomía de Cataluña. Madrid: Ministerio de Administraciones Públicas.

(2006) "Las cuestiones competenciales en los actuales procesos de reforma de los Estatutos". Revista General de Derecho Constitucional. Iustel.

- Biglino Campos, P. (2006(: "La reforma de los Estatutos de Autonomía". Revista Jurídica de Castilla y León. Valladolid.

- Bosch I Roca, N. (2006) "El model de finançament autonòmic del projecte de reforma de l'Estatut de Catalunya". Revista Catalana de Dret Públic, $\mathrm{N}^{\circ} 32$.

- Caamaño, F. (2007) "Sí, pueden (Declaraciones de Derechos y Estatutos de Autonomía)". Revista Española de Derecho Constitucional, $N^{\circ} 79$.

- Cabellos Espiérrez, M.A. (2006) "Cataluña" (Crónicas sobre la actual reforma de los Estatutos de Autonomía). Revista General de Derecho Constitucional. Iustel.

- Corretja Torrens, M. (2006) "La reforma del Estatuto de Autonomía de Cataluña". En Ortega Álvarez, L. (director) La reforma del Estado Autonómico, Madrid: Centro de Estudios Políticos y Constitucionales.

- I Viver Pi-Sunyer, C. (2005): "La reforma de l'Estatut d'Autonomia i les competències de la Generalitat". Activitat Parlamentària, $\mathrm{N}^{\circ} 7$.

- De Carreras Serra, F. (2005) "Reflexiones sobre la propuesta de nuevo Estatuto de Cataluña". Teoría y Realidad Constitucional, $\mathrm{N}^{\circ} 16$. 
- Carrillo, M. (2007) "Los derechos, un contenido constitucional de los estatutos de autonomía". Revista española de Derecho Constitucional, $\mathrm{N}^{\circ} 80$.

- De la Quadra-Salcedo Janini, T. (2004) “¿Es el Estatuto de Autonomía una norma capaz de modular el alcance de la legislación básica del Estado?". Revista Española de Derecho Constitucional, N ${ }^{\circ} 70$.

(2006) "Después del referéndum de Cataluña". Claves de Razón Práctica $\mathrm{N}^{\circ} 164$.

- Castellà Andreu, J.M. (2004) La función constitucional del Estatuto de Autonomía de Cataluña. Barcelona: Institut d'Estudis Autonòmics.

- Cruz Villalón, P. (2006): "La reforma del Estado de las Autonomías", a Revista d'Estudis Autonòmics i Federals, $\mathrm{N}^{\circ} 2$.

- Díez-Picazo, Luis Ma (2006) “PPueden los Estatutos de Autonomía declarar derechos, deberes y principios?. REDC $\mathrm{N}^{\circ} 78$.

- Fernández Farreres, G. (2005) "El Estatuto de Cataluña y la Reforma del Estado" a Repertorio Aranzadi del Tribunal Constitucional, No 18.

- Fernández, A. (2004) Aproximación al debate semántico y jurídico en torno a las nociones nación, nacionalidades y regiones. Madrid: Ministerio de Administraciones Públicas.

- Ferreiro lapatza, J.J. (2006) "El sistema de financiación autonómica de Cataluña: Estatuto y Constitución”. Revista Catalana de Dret Públic, $\mathrm{N}^{\circ} 32$.

- Ferreres Comella, V./ Biglino Campos, P./ Carrillo, M. (2006) Derechos, deberes y principios en el nuevo Estatuto de Autonomía de Catalunya. Madrid: Foro Territorial. La estructura territorial del Estado $\mathrm{n}^{\circ} 8$, Centro de Estudios Políticos y Constitucionales.

- Ferret Jacas, J. (2005): "Estatut d'autonomia: funció constitucional i límits materials" Revista Catalana de Dret Públic, $\mathrm{N}^{\circ} 31$.

- Font I Llovet, T. (2004): La participación de los Municipios en las Comunidades Autónomas ante la reforma de los Estatutos de Autonomía. Madrid: Ministerio de Administraciones Públicas.

- Font I llovet, T./ Velasco Caballero.F./ Ortega Álvarez, L. (2006) El régimen local en la reforma de los Estatutos de Autonomía. Madrid: Foro La Estructura Territorial del Estado n ${ }^{\circ}$ 6. Centro de Estudios Políticos y Constitucionales.

- García Novoa, C. (2006) "El sistema de financiación en la reforma del Estatuto catalán ¿es compatible con el orden constitucional?”. Revista Catalana de Dret Públic, $\mathrm{N}^{\circ} 32$.

- García Ruiz, J. L./ Girón Aguilera, E. (2005) "La financiación autonómica ¿competencia constitucional o estatutaria?". Revista Española de Derecho Constitucional, $\mathrm{N}^{\circ} 75$.

- González, M.I./ Vidal, J. M. (2004) Informe sobre las principales materias incluidas en la reforma de los Estatutos de Autonomía. Madrid: Ministerio de Administraciones Públicas. 
- Jiménez Asensio, R. (2004): "Reforma del Estatuto de Cataluña y ampliación de competencias", Revista Vasca de Administración Pública, núm. 70, 2004, pp. 97-123.

- Lasagabaster, I. (2005): "La reforma de los Estatutos de autonomía: una reflexión sobre su teoría y su práctica actuales". Revista Catalana de Dret Públic, $\mathrm{N}^{\circ} 31$.

- López Medel, J. (2006) El Estatuto de Catalunya como instrumento jurídico (Una meditación sobre España). Zaragoza: Fragua.

- Maragall I Mira, P. et al. (2006) Discursos pronunciats al Parlament de Catalunya en la sessió d'aprovació de la proposta de Reforma de l'estatut d'Autonomia de Catalunya. Barcelona: Generalitat de Catalunya, Departament de Presidència.

- Martín Fernández, J. (2006) "La incidencia del nuevo modelo de financiación autonómica en las haciendas locales de Cataluña: autonomía local y reserva de ley". Revista Catalana de Dret Públic, $\mathrm{N}^{\circ} 32$.

- Ortega Álvarez, L. (2005) La redefinición por los estatutos de autonomía de la distribución territorial del poder contemplado en la Constitución, Madrid: Ministerio de Administraciones Públicas.

- Ripollés, M.R. (2006) "La reforma de los Estatutos de Autonomía". Revista General de Derecho Constitucional. Madrid: Iustel.

- Solozabal Echavarría, J.J. (2003) "Sobre las reformas estatutarias y la propuesta del Parlamento catalán". La reforma de los Estatutos de Autonomía. Valladolid: Junta de Castilla y León/Revista Jurídica de Castilla y León, pp. 121-145.

- (2004) Consideraciones sobre las reformas estatutarias, Madrid: Ministerio de Administraciones Públicas.

- Tajadura Tejada, J. (2005): "La reforma del Estatuto de Cataluña: propuestas y límites". La reforma de los Estatutos de Autonomía. Con especial referencia al caso de Cataluña. Madrid: Centro de Estudios Políticos y Constitucionales.

- VIDAL, J.M. Coordinador (2004) Informe sobre el marco constitucional de la reforma de los estatutos de autonomía: (proceso y tiempos). Madrid: Ministerio de Administraciones Públicas.

- Vilalta Ferrer, M.T. (2006) "La incidència del nou model de finançament autonòmic a les hisendes locals de Catalunya (aspectes econòmics)". Revista Catalana de Dret Públic, $\mathrm{N}^{\circ} 32$.

- Vintró Castells, J. (2006) "La actividad de las Comunidades Autónomas. Cataluña", Informe Comunidades Autónomas 2005. Barcelona: Instituto de Derecho Público.

- Viver Pi-Sunyer, C. (2005) "La reforma de los Estatutos de Autonomía". La reforma de los Estatutos de Autonomía. Con especial referencia al caso de Cataluña. Madrid: Centro de Estudios Políticos y Constitucionales. 
(2005) "En defensa dels Estatuts d'autonomia com a normes jurídiques delimitadores de competències. Contribució a una polèmica juridicoconstitucional". Revista d'Estudis Autonòmics i Federals, $\mathrm{N}^{\circ} 1$. 